\title{
Bhisho corruption-busting now the national pilot
}

A slick 'MassMart-like' national pilot programme for ethical procurement and monitoring, backed by a high-tech group of national government agencies, kicked off last month in the Eastern Cape health department where proponents claim it will cut fraud and wastage by up to $80 \%$.

The provincial department, chosen for its unrivalled success in corruption-busting and steady return to functionality, has for 2 years been led by canny former Port Elizabeth businessman, Dr Siva Pillay. It may prove the crucible for some sorely needed national alchemy, if talking to Pillay and some of his value-driven 'social compact' practitioners is anything to go by.

One member of the special multiagency work group (MAWG) lists a constraint to their investigation as the wholesale theft and sale of documentation to a recycling company.

Coming off a R424 million budget cut (2012/13), Pillay initially appears a bit too sanguine for someone upon whom so much depends - until he starts to outline how and where his 'working smarter' approach has already saved well in excess of this amount (more on this later). His results led to national Finance Minister Pravin Gordhan and SA Revenue Service (SARS) Commissioner, Ivan Pillay (formerly SARS head of Compliance), setting up a multi-agency task team to help overhaul his department's procurement of equipment and services. The scale of the endemic fraud and corruption that's emerging is breathtaking. It ranges from the relatively small-scale 174 spouses of health department staff linked to companies illegally paid some R9 million, through 780 staffers and their spouses illegally drawing social grants and housing subsidies and R19 million of unaccounted assets transferred from head office to districts, to R450 million in ghost contracts. One member of the special multi-agency work group (MAWG) lists a constraint to their investigation as the wholesale theft and sale of documentation to a recycling company.

Consisting of members of the Hawks (Priority Crimes Unit), the Special Investigations Unit, the Assets Forfeiture Unit, national and provincial treasury, SARS, and backed by Price Waterhouse Coopers and other top private auditing companies, the team will use 14 interlinked 'hubs' across the province to reform the entire supply chain management system. The new filters will begin with 'declaration management' (tender-holders or applicants declaring all familial/personal links), companies and intellectual properties (CIPRO) searches, cross-checks with PERSAL (the personnel salary system) and Home Affairs identity documentation - all of this linked to the existing supplier databases. The qualifications of each and every supplier will be painstakingly verified. The MAWG will then move on to the 'top 100' items being procured, putting in place 'demand planning and management' to create new or revised procurement plans - with dodgy existing contracts earmarked for cancellation or renegotiation over terms and/or conditions.

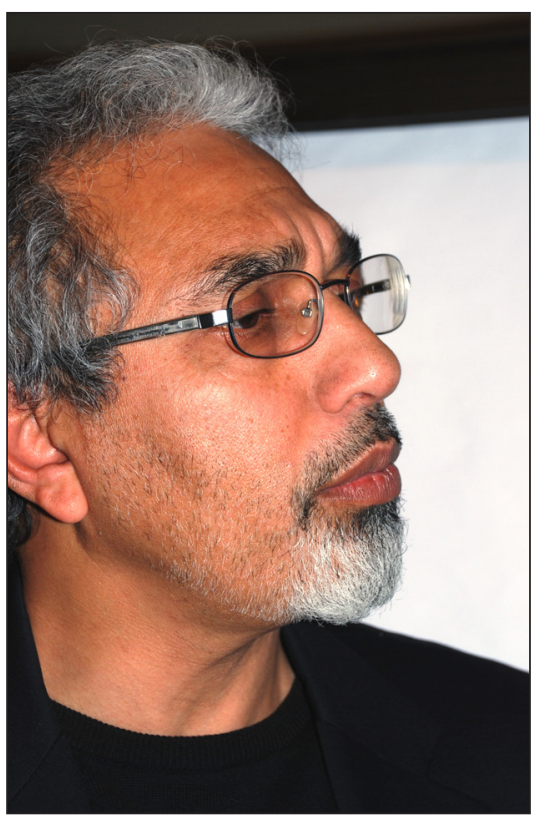

Ivan Pillay, Commissioner, South African Revenue Service.

\section{Information web will snag crooks}

The 14 'hubs' will be spread out across the health districts, metro complexes, head office (including pharmacy) and regional hospitals to act as a filtering system to increase the integrity and quality of supply and thus root out more corrupt officials and privateers milking the system.

From June the hubs should be connected via a new virtual private network (VPN), which will enable instant electronic access to data and vastly enhance patient tracking and management, something that the IT-savvy Pillay initiated soon after taking office. The VPN, backed by a redundancy network, will also link the $60 \%$ of hospitals currently without connectivity to the 865 clinics and 92 community health centres (also enabling broader bandwidth for the 28 currently linked hospitals and enabling several telemedia lecture theatres).

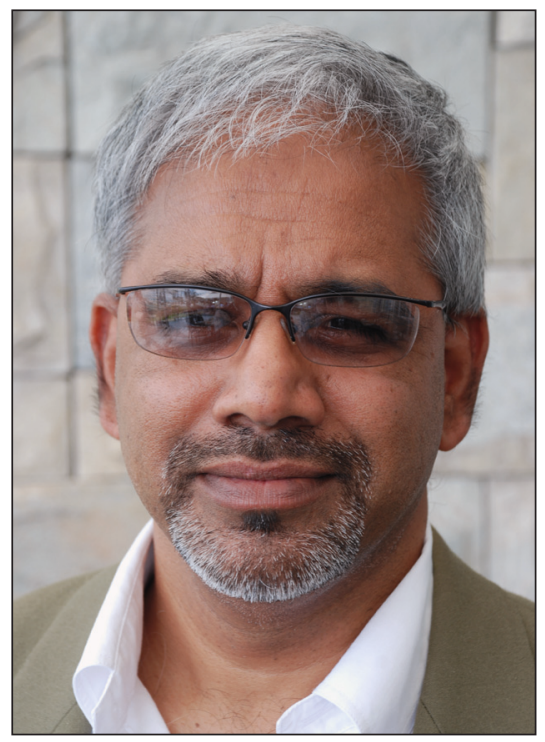

Dr Siva Pillay, Director-General, Eastern Cape Health Department.

By uncovering 'ghost contracts' and stopping payments, he's recovered the whopping extra R450 million, mostly via a pragmatic approach to several cases. An example is a company that billed R26 million for non-existent maintenance. Its directors were told: 'Walk away without payment and we won't charge you criminally. They walked. Scores of very senior staff resignations were impelled by this principle, saving months of salaried and expensive arbitration and speeding up management change.

In his 2 years as Director-General of Health, Pillay has forced the resignation and/ or disciplinary hearing/criminal charging of more than 1200 people, most of them health department staff helping themselves to money meant for patient care. Last year alone, Pillay's core provincial turnaround team recovered R89 million in cash following disciplinary hearings and sackings involving fraud, being drunk-on-duty and 
assault. He's been targeted by some powerful internal political groupings ${ }^{1}$ and confronted by a gunman in a deserted Bhisho parking lot, escaping only by releasing his two highly trained Alsatian dogs fortuitously in his bakkie. ${ }^{2}$ By uncovering 'ghost contracts' and stopping payments, he's recovered the whopping extra R450 million, mostly via a pragmatic approach to several cases. An example is a company that billed R26 million for non-existent maintenance. Its directors were told: 'Walk away without payment and we won't charge you criminally.' They walked. Scores of very senior staff resignations were impelled by this principle, saving months of salaried and expensive arbitration and speeding up management change. (At the time of writing, the tally of health staff suspended on pay at home was down to 56.)

\section{Taking on the unions, improving delivery}

All of this before the national task team kicks into high gear. Pillay has taken on the unions, finally reaching settlement over the 1000 staff irregularly promoted (beyond their qualifications) when the former homelands (Ciskei/Transkei) were united in 1994. From 31 March this year all reverted to their old lower gradings, plugging a protracted R80 million per annum illicit salary black-hole. A wildcat strike by some 220 nurses at the Nelson Mandela Academic Hospital Complex last month (in alleged breach of court undertakings) was met with disciplinary notices served on 120 of them. The message to their union: 'We play by the book, but bring it on.' Asked by Izindaba how different the new task team checks and balances were to the systems he initially encountered, Pillay replied, 'None of this was happening before. It was all paper-based. I was flying this plane blind. For the first time we're now getting quality information which helps us manage managers. Before that there were millions of transactions and I didn't know what was going on. Basically we're

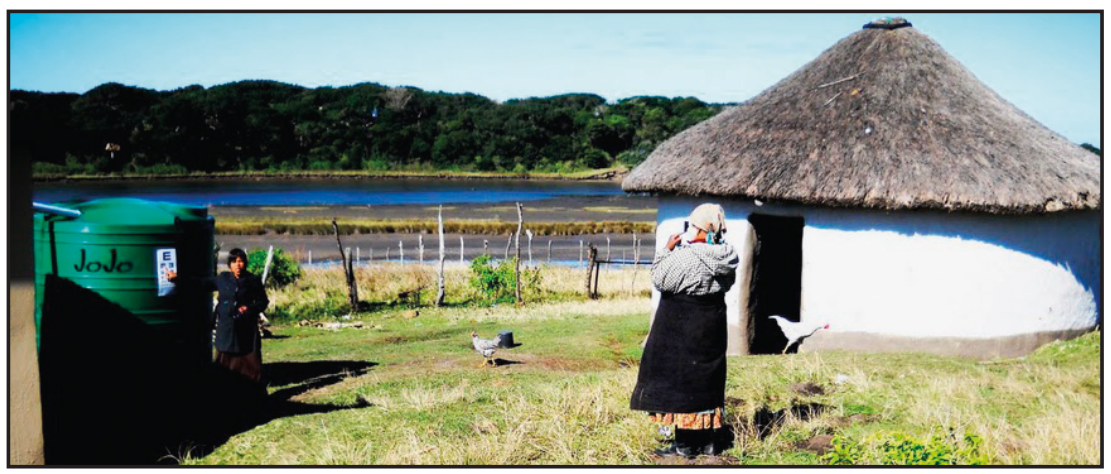

An improvised eye test at Nquileni Village near Coffee Bay in the Eastern Cape. increasing visibility with a system of checks and balances and controls and monitoring. The first region to come under the spotlight is the province's heartland, the Amathole district (population 1.7 million), embracing the East London Hospital Complex, King William's Town, Mdantsane and the administrative capital Bhisho. By the time of Izindaba going to print, the amount of goods and services 'required' had already decreased (granted it was early days and the quantities were marginal, but a clear trend was appearing), leading Pillay to believe an iceberg of non-existent services is emerging.

Coming off a R424 million budget cut (2012/13), Pillay initially appears a bit too sanguine for someone upon whom so much depends - until he starts to outline how and where his 'working smarter' approach has already saved well in excess of this amount.

Actuaries conservatively project that savings by the new combined task team

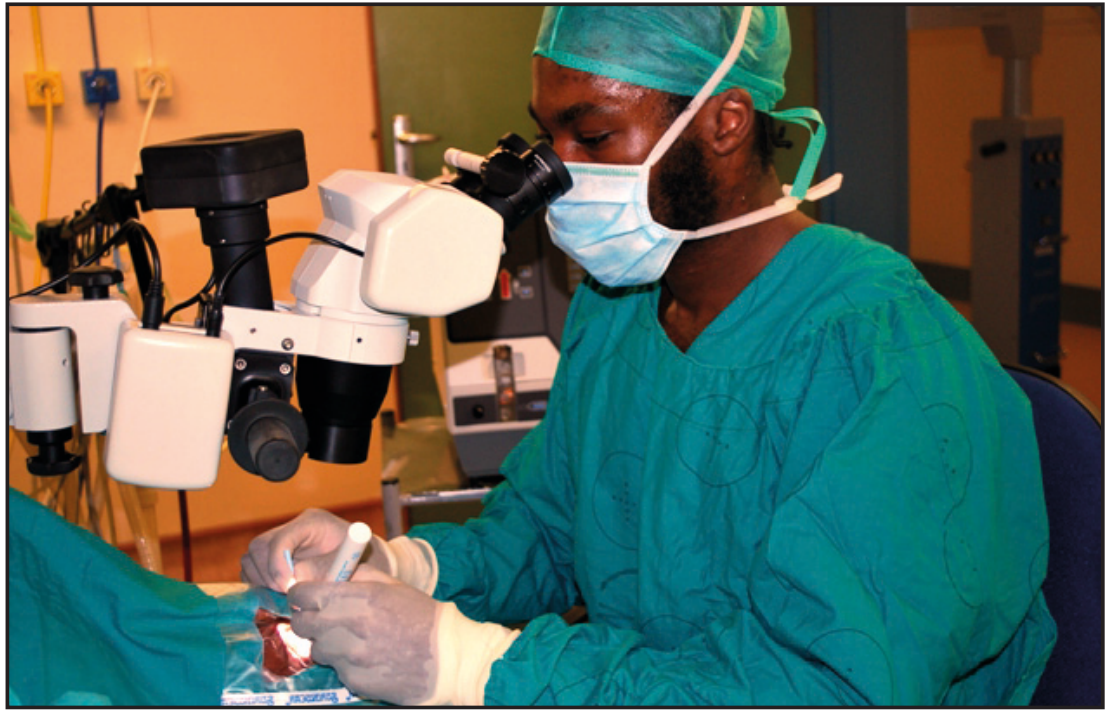

will exceed R200 million in general health services and R250 million in medicines (leakage, expiry, rotation and patient wastage) in the first year alone. Besides his existing successes in recovering taxpayers' money, what bolsters Pillay's confidence in the medicines projection is what he already knows about his antiretroviral drug supplies (ARVs). 'I have 179000 patients on ART but when I look at the number of ARVs I bought, it's for about 200000 (patients). You have to ask where the rest of the drugs are going to. And I don't even have the hypertension and diabetes figures yet!' The pharmaceutical benefit management system will stop the leakage and address mismanagement, dysfunction, corruption and wastage by patients, he believes.

\section{Expanded delivery platform 'unsustainable'}

When his health budget was presented to the Eastern Cape legislature on 20 March this year, Pillay fell victim to negative local media coverage after publicly calculating that he would need an impossible extra R9 billion to fill 27267 vacant posts. He revealed that vacancy rates in critical posts had shot up from $28 \%(09 / 10)$ to $44 \%(10 / 11)$. However, his central point was missed (by all but Gordhan whose mid-term budget allocation will probably mitigate the initial cut). The earth-shaking staff vacancy rift was politically created - by a rapid and ambitiously expanded service delivery platform which quickly reached 'unsustainable proportions'. Pillay's first crack at radically rationalising this platform and its attendant equipment and human resources focuses on pure functionality - and has received scant media attention. He told Izindaba: 'Our district hospitals have turned 
into glorified clinics, in spite of them putting in for expensive equipment which they'll never use (the standard hospital management argument being that this will attract clinical staff). Of the 66 district hospitals, only 11 are fully functional. So we've concentrated our resources on 28 to get them fully functional. It's simple arithmetic; consolidate and make things work properly, he says. He cites linear accelerators, one of each wanted by Mthatha and Livingstone Hospitals (to match the one at Frere Hospital); 'I asked them how many cancer patients we have and it turns out we don't need three accelerators. That alone saved R34 million'

\section{Crichton has set up sub-district 'social compact committees' to help identify pupils between grades 9 and 12 for streaming into health professions bursaries tailored to each district's needs.}

Moving to the 'front-end' of the service delivery vehicle, human resource development (HRD), Pillay has the enthusiastic Dr Andrew Crichton analysing for the first time ever the HR needs of 28 health sub-districts based on the rationalised service delivery platform. Crichton has set up sub-district 'social compact committees' to help identify pupils between grades 9 and 12 for streaming into health professions bursaries tailored to each district's needs. Using the HR supply streams of community service conscripts, foreign qualified workers, standard recruiting practices (e.g. provincial health website) and bursars, he aims to balance recruitment with local needs. Bursars will be filtered by relevant subject marks, a

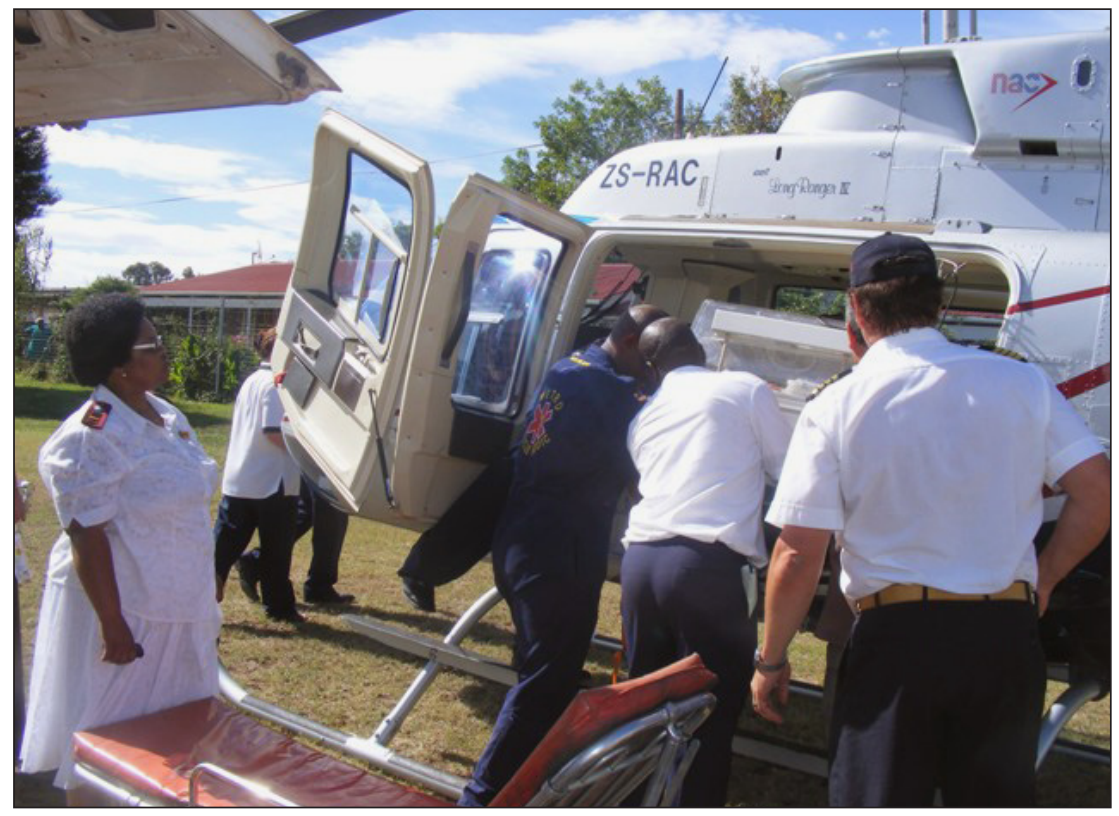

Eastern Cape rescue team - a service historically abused to transport private patients for personal gain..

family income below R6 500 per month and students already studying but financially constrained by events, with involvement in community projects a pivotal criterion.

\section{Beyond the 'desperation of poverty'}

'We want to move beyond the desperation of poverty to the values of Ubuntu and commitment, compassion and solidarity. If you're not already showing commitment to serving the community then we know you're not a good bursar,' Crichton added. A huge critic of the 'chasing numbers and ratios', and 'teaching for export' approach to solving South Africas human resources crisis, the educationist outlines four value-driven processes: seeking out people aligned to your needs, developing them to be capable and engaging them to perform, and finally, inspiring them to commit. Using value systems as standards of judgement instead of just targets, he believes, 'changes the entire picture'.

'In the past it was assumed that if you're poor and black you had the right attitude. Telling us that $40 \%$ of rural recruits will return to us spells failure. It's about who we bring into the system, not how many. Thus are change-agents created, he argues.

\section{Chris Bateman}

chrisb@hmpg.co.za

1. Bateman C. E Cape health chief hits back at 'jobs for pals' charges. S Afr Med J 2011;101:610-612

2. Bateman C. Corruption busting a real health threat. S Afr Med J 2011;101:360-362. 